\title{
ANALISIS KEUNTUNGAN KERAJINAN BAMBU TUTUL DI UD BETRIS KELURAHAN MERAS KECAMATAN BUNAKEN KOTA MANADO
}

\author{
Deisi Wongkar \\ Agnes Estephina Loho \\ Theodora M. Katiandagho
}

\begin{abstract}
The purpose of this study was to analyze the profits of souvenir key chains, miniature of large traditional houses, miniature of small traditional houses and miniature flowers at UD Betris. The data used in this study are primary data and secondary data. Primary data is data obtained by interviewing with owners of UD Betris spotted bamboo handy handycrafts in Meras Village, Bunaken District, Manado City. Secondary data was obtained from the internet through Google Scholar in the form of scientific journal articles and books related to this research topic. The profits of this business are different according to the type of handycrafts. The highest profit was obtained from the sale of large miniature traditional houses, namely $R p .1,609,425$; followed by the advantages of small traditional miniature houses of Rp. 716,480; the profit obtained from miniature interest is Rp. 179,165; while the lowest profit from the souvenir key chain is Rp. 5,898. ${ }^{*}$ rr+eprm*
\end{abstract}

Keywords : Profit Analysis, Craft, Bamboo, Manado City

ABSTRAK
Tujuan penelitian ini yaitu untuk menganalisis keuntungan souvenir gantungan kunci, miniatur rumah adat besar, miniatur rumah adat kecil dan miniatur bunga pada UD Betris. Data yang digunakan dalam penelitian ini adalah data primer dan data sekunder. Data primer merupakan data diperoleh melalui wawancara langsung dengan pemilik kerajinan bambu tutul UD Betris di Kelurahan Meras, Kecamatan Bunaken, Kota Manado. Data sekunder diperoleh dari internet melalui google cendekia berupa artikel jurnal ilmiah dan buku yang berhubungan dengan penelitian ini. Keuntungan dari usaha ini adalah berbeda-beda menurut jenis kerajinannya. Keuntungan tertinggi diperoleh dari penjualan miniatur rumah adat besar yaitu Rp 1.609.425,-; di ikuti oleh keuntungan dari miniatur rumah adat kecil sebesar Rp 716.480.-; keuntungan yang diperoleh dari miniatur bunga sebesar Rp 179.165,-; sedangkan keuntungan terendah dari souvenir gantungan kunci sebesar Rp 5.898.- . ${ }^{* 1 r r+e p r m *}$

Kata kunci: analisis keuntungan, kerajinan, bambu, Kota Manado

\section{PENDAHULUAN}

\section{Latar Belakang}

Pembangunan kehutanan merupakan upaya penyelenggaraan pengelolaan sumber daya secara lestari dan pemanfaatan hutan sebesar-besarnya untuk kemakmuran rakyat. Pelaksanaan pembangunan kehutanan dilakukan secara berencana, menyeluruh, terpadu, terarah, bertahap, dan berkelanjutan untuk meningkatkan kemampuan sumber daya hutan dan kehutanan dalam memberikan hasil-hasil yang optimal, baik berupa barang maupun jasa. Pelaksanaan pembangunan kehutanan tersebut tentu harus tetap menjaga kelestarian sumber daya alam dan kelangsungan fungsi serta mutu lingkungan hidup dan peningkatan fungsi sosial ekonomi hutan. Tujuan pembangunan kehutanan adalah mempertahankan keanekaragaman hayati, memperluas kesempatan kerja dan berusaha meningkatkan sumber devisa negara (Arief, 2001). 
Sumber daya hutan (SDH) Indonesia menghasilkan berbagai manfaat yang dapat dirasakan pada tingkatan lokal, nasional, maupun global. Manfaat tersebut terdiri atas manfaat nyata yang terukur (tangible) berupa hasil hutan kayu, hasil hutan non kayu seperti rotan, bambu, damar dan lain-lain, serta manfaat tidak terukur (intangible) berupa manfaat perlindungan lingkungan, keragaman genetik dan lain-lain (Nurfatriani, 2006).

Bambu merupakan produk hasil hutan nonkayu yang telah dikenal dan sangat dekat dengan kehidupan masyarakat umum karena pertumbuhannya ada di sekeliling kehidupan masyarakat. Bambu termasuk dalam tanaman Bamboidae anggota subfamilia rumput, keanekaragaman jenis bambu di dunia sekitar 1250 - 1500 jenis, sedangkan di Indonesia memiliki hanya $10 \%$ sekitar 154 jenis bambu (Setiawan, 2017).

Industri rumah tangga merupakan salah satu komponen dari sektor industri pengolahan yang memiliki andil yang besar dalam menciptakan lapangan pekerjaan, walaupun sifat usahanya masih memerlukan pembinaan secara terus menerus. Kegiatan industri rumah tangga memiliki kaitan yang dekat dengan mata pencaharian pertanian di daerah pedesaan. Pada mulanya kegiatan ini merupakan pekerjaan sampingan para petani dan penduduk desa yang memiliki arti sebagai sumber penghasilan tambahan dan musiman, namun sekarang banyak industri rumah tangga yang dapat memberikan penghasilan yang lebih besar dibandingkan penghasilan dari sektor pertanian.

Setiap industri rumah tangga mestinya mempunyai pengetahuan yang pasti mengenai penghasilan yang di terima dalam satu jangka waktu tertentu. Berbagai jenis industri rumah tangga yang ada salah satunya adalah industri kerajinan. Banyak daerah di Indonesia yang berkembang perekonomiannya lewat industri kerajinan. Konsep industri kerajinan merupakan aktivitas yang berbasis kreativitas yang mana nantinya berpengaruh terhadap perekonomian dan kesejahteraan masyarakatnya, serta sektor industri kerajinan ini mampu menyerap tenaga kerja yang sangat tinggi.
Industri rumah tangga menyiratkan adanya kelemahan-kelemahan yang sifatnya potensial terhadap timbulnya masalah. Hal ini menyebabkan berbagai masalah internal terutama yang berkaitan dengan pendanaan tampaknya sulit untuk mendapatkan solusi yang jelas. Keberadaan industri memiliki peranan yang sangat penting dalam perekonomian terutama dalam aspek-aspek seperti kesempatan kerja, pemerataan pendapatan, pembangunan ekonomi di pedesaan dan lain-lain. Di Provinsi Sulawesi Utara khususnya Kelurahan Meras Kecamatan Bunaken terdapat industri bambu yang memproduksi kerajinan berupa souvenir dan miniatur.

Industri kerajinan bambu tutul UD Betris merupakan usaha yang memproduksi kerajinan souvenir dan miniatur yang berdiri pada tahun 2015. Kerajinan bambu tutul berlokasi di Kelurahan Meras Kecamatan Bunaken Kota Manado. Produk kerajinan ini sudah dikenal di sebagian daerah Kota Manado karena merupakan satu-satunya kerajinan souvenir dan miniatur di Kelurahan Meras yang mengolah bambu tutul untuk kerajinan. Produk yang dihasilkan selama tahun 2018 ada 10 jenis yaitu, souvenir gantungan kunci tetengkoreng dan sandal, miniature rumah adat minahasa besar dan kecil, miniature bunga, miniature kursi set, miniature gereja, miniature kapal, miniature zeropoint, miniature pesawat.

Kerajinan bambu tutul UD Betris tidak memiliki laporan keuangan. Tidak ada perhitungan yang pasti tentang berapa besar biaya yang dikeluarkan dan berapa besar penerimaan. Juga tidak diketahui berapa besar keuntungan yang diterima oleh usaha UD Betris. Sehingga perlu dianalisis berapa keuntungan per jenis produk kerajinan dari UD Betris karena tujuan dari setiap usaha yang didirikan pada umumnya adalah untuk memperoleh keuntungan yang semaksimal mungkin. Jenis kerajinan yang akan dianalisis hanya 4 dilihat dari paling dipesan dan diproduksi yaitu, souvenir gantungan kunci tetengkoreng, miniature rumah adat minahasa besar dan kecil, dan miniature bunga.

\section{Rumusan Masalah}

Berdasarkan latar belakang yang telah dikemukakan, maka rumusan masalah dalam penelitian ini yaitu berapa besar keuntungan untuk produk souvenir gantungan kunci, miniature rumah adat besar, miniature rumah adat kecil dan miniature bunga pada usaha UD Betris. 


\section{Tujuan Penelitian}

Tujuan penelitian ini yaitu untuk menganalisis keuntungan untuk produk souvenir gantungan kunci, miniature rumah adat besar, miniature rumah adat kecil dan miniature bunga pada usaha UD Betris.

\section{Manfaat Penelitian}

Penelitian ini diharapkan dapat memberikan manfaat bagi:

1. Perusahaan

Penelitian ini diharapkan dapat dijadi informasi dan referensi tambahan dan bahan pertimbangan bagi kerajinan bambu tutul UD. Betris untuk membuat keputusan dalam rangka mencapai keuntungan yang maksimal

2. Peneliti

Penelitian ini diharapkan dapat menambah ilmu dan wawasan tentang analisis keuntungan serta dapat mengetahui realita di lapangan dan membandingkan teori serta menambah pengetahuan dan pengalaman, serta menerapkan ilmu yang diperoleh selama kuliah. Penelitian ini diharapkan dapat memberikan informasi atau pengetahuan baru kepada pihak-pihak yang berkepentingan dan dapat bermanfaat sebagai bahan perbandingan untuk penelitian selanjutnya.

\section{METODE PENELITIAN}

\section{Tempat dan Waktu Penelitian}

Penelitian ini dilaksanakan pada kerajinan bambu tutul UD Betris Kelurahan Meras Kecamatan Bunaken Kota Manado. Kegiatan penelitian ini dilakukan 5 bulan, mulai dari tahap persiapan hingga penyusunan laporan yakni mulai bulai Januari 2018 sampai bulan Mei 2018.

\section{Metode Pengumpulan}

Data yang digunakan dalam penelitian ini adalah data primer dan data sekunder. Data primer merupakan data mentah yang diambil oleh peneliti diperoleh dilapangan langsung dari sumbernya yang dalam penelitian ini adalah pemilik usaha kerajinan bambu tutul UD Betris Kelurahan Meras Kecamatan Bunaken Kota Manado. Data ini diperoleh dari wawancara secara langsung.
Wawancara dilakukan melalui tatap muka dan tanya jawab langsung antara peneliti dan narasumber. Sedangkan data sekunder diperoleh dari studi kepustakaan berupa literature, sumber tertulis atau dokumen yang memiliki relevansi dengan penelitian ini.

\section{Konsep Pengukuran Variabel}

Variabel-variabel yang akan di ukur dalam penelitian ini adalah:

1. Produksi yaitu jumlah produksi kerajinan bambu tutul untuk masing-masing produk, dinyatakan dalam satuan unit.

2. Harga merupakan harga jual kerajinan bambu tutul untuk masing-masing produk kerajinan, dihitung dalam satuan rupiah per unit.

3. Biaya produksi yaitu besarnya biaya yang dikeluarkan dalam proses produksi kerajinan, masing-masing produk terdiri dari:

a. Biaya Tetap

1) Biaya Penyusutan Mesin

Rumus yang digunakan adalah :

$$
\text { Biaya Penyusutan Alat }=\frac{\text { Harga Beli }- \text { Nilai Sisa }}{\text { Umur Ekonomis }}
$$

\section{2) Pajak PBB}

4. Penerimaan yaitu perkalian antara produksi yang diperoleh dengan harga jual yang dinyatakan dalam rupiah $(\mathrm{Rp})$

5. Keuntungan yaitu nilai yang diperoleh dari hasil penjualan dikurangi dengan biaya yang dikeluarkan yang dinyatakan dalam rupiah (Rp).

\section{Analisis Data}

Data yang dikumpulkan dalam penelitian disajikan dalam bentuk deskriptif ini kemudian dianalisis dengan menggunakan analisis keuntungan yaitu dengan menghitung selisih antara penerimaan dengan biaya yang digunakan. Dilanjutkan dengan rumus analisis Revenue Cost Ratio (R/C).

Rumus yang digunakan sebagai berikut:

$$
\boldsymbol{\pi}=\mathbf{T R}-\mathbf{T C}
$$

Dimana :

$$
\begin{array}{ll}
\pi(\text { Profit }) & : \text { Keuntungan } \\
\text { TR }(\text { Total Revenue }) & : \text { Penerimaan Total } \\
\text { TC }(\text { Total Cost }) & : \text { Total Biaya Produksi } \\
& \text { TR }=\mathbf{Q} \mathbf{x} \mathbf{P}
\end{array}
$$


Dimana :

TR (Total Revenue) : Penerimaan Total (Rp)

Q (Quantity) : Jumlah Produksi

$\mathrm{P}$ (Price) : Harga dari hasil produksi

(Rp)

$$
\mathrm{TC}=\mathrm{FC}+\mathrm{VC}
$$

Keterangan :

TC (Total Cost)

: Total Biaya

FC (Fixed Cost)

: Biaya Tetap

VC (Variabel Cost) : Biaya Variabel

Kemudian untuk mengetahui apakah UD

Betris menguntungkan atau tidak, dapat digunakan rumus sebagai berikut:

Dimana :

$$
\boldsymbol{\alpha}=\mathbf{R} / \mathbf{C}
$$

$\alpha \quad$ : Perbandingan antara penerimaan dan biaya

$\mathrm{R}$ (Revenue) : Penerimaan

C (Cost) : Biaya

Apabila :

$\mathrm{R} / \mathrm{C}<1$, berarti usaha UD Betris mengalami kerugian

$\mathrm{R} / \mathrm{C}=1$, berarti usaha UD Betris ini tidak untung atau rugi

$\mathrm{R} / \mathrm{C}>1$, berarti Usaha UD Betris mengalami keuntungan.

\section{HASIL DAN PEMBAHASAN}

\section{Gambaran Umum Usaha UD Betris}

Usaha kerajinan bambu tutul UD Betris merupakan usaha pengolahan bambu tutul menjadi bentuk kerajinan yang ada di kota manado. Usaha ini didirikan pada oktober tahun 2015 oleh Ibu Bertha Mansauda yang beralamat di Kelurahan Meras Lingkungan 3 Kecamatan Bunaken Kota Manado. Latar belakang berdirinya usaha adalah berawal dari pemilik yang mempunyai keterampilan membuat kerajinan, sehingga dari keterampilan dan dengan tekad kuat maka Ibu Bertha mencoba untuk mendirikan usaha kerajinan bambut tutul yang diberi nama UD Betris.

Produksi UD Betris pada awal berdiri usaha tidak terlalu banyak. Kegiatan produksi dilakukan setiap minggu dikarenakan belum adanya pelanggan tetap yang membeli produk kerajinan bambu tutul. karena itu kegiatan produksi tidak dilakukan secara rutin. Kegiatan produksi kerajinan bambu tutul didasarkan pada pesanan dari konsumen. Pemilik usaha mempromosikan usahanya dengan mengunjungi tempat-tempat tertentu yang mempunyai peluang untuk membeli dalam jumlah yang besar. Setelah melakukan promosi diberbagai tempat, hasil dari produksinya Ibu Bertha sendiri yang mendistribusikan ke toko-toko pusat perbelanjaan, dinas sosial, dan dinas pariwisata sekitar Kota Manado. Alat musik saxophone merupakan kerajinan pertama yang dibuat oleh beliau. Selanjutnya dikembangkan kerajinan gantungan kunci, bunga, dan rumah panggung minahasa. Semakin lama usaha Ibu Bertha semakin dikenal.

\section{Lokasi Usaha}

Keadaan disekitar lokasi usaha cukup baik, dengan kata lain usaha ini tidak berpengaruh negatif terhadap masyarakat sekitar dan tidak mengganggu atau mencemari lingkungan sekitar. Usaha ini justru menjadi peluang dalam membantu masyarakat sekitar dalam hal penyerapan tenaga kerja karena pemilik usaha berasal dari masyarakat setempat.

Lokasi usaha tidak begitu strategis hal ini dikarenakan lokasi tidak terlalu dekat dengan pusat kota. Sarana dan prasaranya tidak begitu menunjang seperti tidak dekat dengan pasar atau pertokoan, dekat dengan jalan raya tetapi angkutan umum sangat terbatas sehingga untuk akses pembelanjaan dan pemasaran terlihat lambat.

\section{Struktur Organisasi}

Struktur organisasi merupakan suatu susunan dan hubungan antara tiap bagian serta posisi yang ada pada suatu organisasi atau perusahaan dalam menjalankan kegiatan operasional untuk mencapai tujuan yang diharapkan. Struktur organisasi menggambarkan dengan jelas pemisahan kegiatan pekerjaan antara yang satu dan yang lain dan bagaimana hubungan aktivitas dan fungsi dibatasi. Usaha kerajinan bambu tutul UD Betris belum memiliki struktur organisasi yang tertulis, akan tetapi dapat digambarkan secara umum mengenai struktur organisasi dari UD Betris. Gambaran umum tentang struktur organisasi UD Betris dapat dilihat pada Gambar 1. 


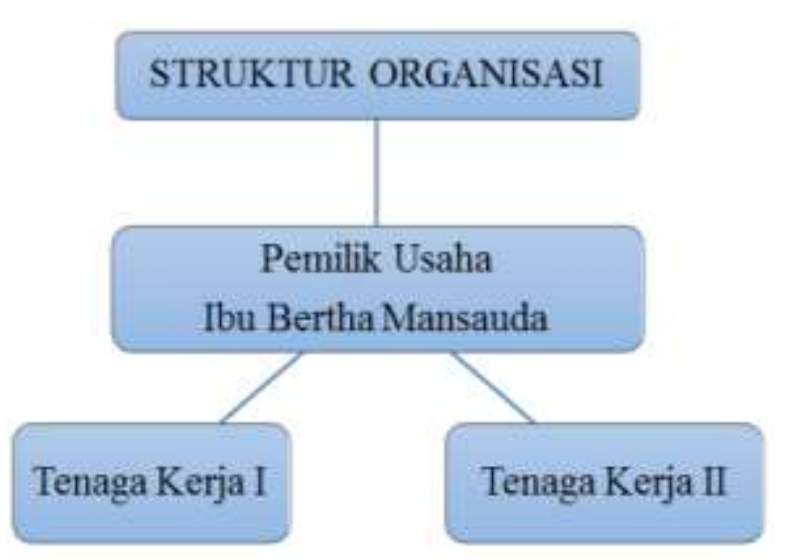

\section{Gambar 1. Struktur Organisasi UD Betris}

Kerajinan bambu tutul UD Betris hanya memiliki 3 orang sebagai tenaga kerja. Dan didalamnya sudah termasuk Ibu Bertha selaku pemilik usaha. Beliau tidak hanya menjadi pemilik tapi juga sebagai pekerja. Beliau mempunyai wewenang mengambil keputusan pada saat tertentu serta bertanggung jawab terhadap segala sesuatu yang terjadi dalam usaha yang dijalankan. Beliau mempunyai peran besar dalam kegiatan produksi, sebab hanya keterampilan ibu bertha yang dapat menghasilkan produk dengan bermacammacam model dan bentuk. Tenaga kerja yang dimiliki tidak bisa membuat kerajinan sama seperti yang beliau hasilkan. Hal ini karena kurangnya keterampilan yang dimiliki oleh tenaga kerja tersebut. Jadi kedua tenaga kerja ditugaskan untuk memotong, menghaluskan/ mengamplas serta membuat gantungan kunci.

\section{Produk}

Produk yang ditawarkan oleh UD Betris adalah kerajinan bambu tutul yang bisa kita jumpai di beberapa pusat perbelanjaan, dibeberapa dinas seperti dinas sosial, dinas koperasi dan dinas perindustrian dan perdagangan. Bisa juga dijumpai pada saat pameran-pameran dan event-event tertentu. Produk yang dihasilkan ada berbagai bentuk dan model desain dari pemilik usaha. Produk kerajinan bambu tutul merupakan satu-satunya produk berbahan baku bambu tutul yang ada di kota manado. Produk yang dihasilkan memiliki keunikan tersendiri. Penggolongan produk miniature/souvenir dapat dilihat pada Tabel 1.
Tabel 1. Penggolongan Kerajinan Miniature/Souvenir UD Betris

\begin{tabular}{llc}
\hline \multirow{2}{*}{ No } & \multicolumn{2}{c}{ Golongan Kerajinan } \\
\cline { 2 - 3 } & \multicolumn{1}{c}{ Miniatur } & Souvenir \\
\hline 1 & Rumah Adat Besar (RAB) & - \\
2 & Rumah Adat Kecil (RAK) & - \\
3 & Bunga & - \\
4 & - & Gantungan kunci \\
\hline \multicolumn{2}{l}{ Sumber : Data primer yang telah diolah 2018 }
\end{tabular}

\section{Biaya Tetap}

Biaya tetap adalah biaya yang tidak tergantung dari besar kecilnya volume produksi, dalam penelitian ini biaya tetap yang dihitung yaitu ada dua yaitu penyusutan mesin dan peralatan dan pajak bumi dan bangunan (PBB).

1. Penyusutan Mesin dan Peralatan

Penyusutan alat merupakan biaya yang perlu dimasukkan ke dalam perhitungan biaya tetap. Biaya penyusutan alat dan mesin yaitu nilai penyusutan selama mesin peralatan itu digunakan. Nilai penyusutan untuk mesin dan peralatan dapat dilihat pada Tabel 2.

Tabel 2 menunjukkan bahwa biaya tetap pada kerajinan bambu tutul UD Betris pada satu bulan yang paling tertinggi adalah lemari pajang dengan penyusutan sebesar Rp 12.500/bulan dan biaya paling rendah adalah pisau ukuran kecil dengan penyusutan sebesar Rp 625/bulan. Sedangkan jumlah keseluruhan biaya penyusutan usaha UD Betris adalah sebesar Rp 33.833/bulan. Kemudian dari jumlah penyusutan tersebut dibagi secara proporsional yaitu untuk miniature rumah adat besar $45 \%$, untuk miniature rumah adat kecil $35 \%$, miniature Bunga $20 \%$, souvenir gantungan kunci $5 \%$.

Tabel 2. Nilai Penyusutan Mesin Dan Peralatan

\begin{tabular}{lr}
\hline Mesin dan peralatan & Penyusutan (Rp) \\
\hline Pisau kecil & 625 \\
Pisau besar & 1.667 \\
Mesin gurinda & 7.292 \\
Parang & 2.708 \\
Gergaji & 1.458 \\
Lemari pajang besar & 12.500 \\
Lemari pajang kecil & 4.583 \\
Kuas & 3.000 \\
\hline Total & 33.833 \\
\hline Sumber : Data primer yang telah diolah 2018
\end{tabular}

\section{Pajak}

Pajak bumi dan bangunan adalah pajak yang ditanggungkan atas tanah dan bangunan karena adanya keuntungan atau kedudukan sosial ekonomi yang lebih baik, karena hak atas tanah dan bangunan yang sudah ditempatinya. PBB UD Betris yaitu sebesar Rp 20.000 untuk 1 tahun. 
Sama halnya dengan penyusutan, pajak juga dibagi secara proporsional yaitu untuk miniature rumah adat besar $45 \%$, untuk miniature rumah adat kecil $35 \%$, miniature Bunga $20 \%$, souvenir gantungan kunci $5 \%$.

Tabel 3 menunjukkan biaya tetap yang paling besar ada pada RAB sebesar Rp 14.200 kerena RAB merupakan jenis produk yang paling besar dan dinilai paling banyak menggunakan mesin dan peralatan serta tempat yang digunakan lebih besar dibandingkan dengan 3 jenis kerajinan lain.

Tabel 3. Total Biaya Tetap Untuk 4 Jenis Kerajinan UD Betris

\begin{tabular}{lccc}
\hline $\begin{array}{c}\text { Jenis Kerajinan } \\
\text { Miniature/Souvenir }\end{array}$ & Penyusutan & Pajak & $\begin{array}{c}\text { Total Biaya } \\
\text { Tetap }\end{array}$ \\
\hline Rumah Adat Besar (RAB) & 13.533 & 667 & $\mathbf{1 4 . 2 0 0}$ \\
Rumah Adat Kecil (RAK) & 11.842 & 583 & $\mathbf{1 2 . 4 2 5}$ \\
Bunga & 6.767 & 333 & $\mathbf{7 . 1 0 0}$ \\
Gantungan Kunci & 1.692 & 83 & $\mathbf{1 . 7 7 5}$ \\
\hline Sumber : Data primer yang telah diolah 2018
\end{tabular}

\section{Biaya Variabel}

Dalam biaya variabel ada biaya bahan baku, upah tenaga kerja dan biaya listrik.

\section{Biaya Bahan Baku}

Ketersedian bahan baku merupakan salah satu faktor utama suatu kegiatan produksi bisa berjalan dengan baik. Oleh karena itu perlu diperhatikan ketersediaan bahan baku dalam pembuatan produk tertentu. Pembuatan kerajinan membutuhkan bahan baku utama yaitu bambu tutul dan bahan tambahannya berupa lem, cat politur, gantungan kunci. Pemenuhan bahan baku utama diperoleh dengan cara memesan setiap minggunya sedangkan untuk bahan tambahan diperoleh dengan cara membeli di pasar dan toko terdekat.

Tabel 4. Penggunaan Bahan Baku Bambu Pada Kerajinan RAB, RAK, Bunga, Gantungan Kunci UD Betris

\begin{tabular}{lcc}
\multicolumn{2}{c}{ RAK, Bunga, Gantungan Kunci UD Betris } \\
$\begin{array}{l}\text { Jenis Kerajinan } \\
\text { Miniature/Souvenir }\end{array}$ & Unit (Ruas) & Unit (Ujung) \\
\hline Rumah Adat Besar (RAB) & 3 & 0,429 \\
Rumah Adat Kecil (RAK) & 2 & 0,286 \\
Bunga & 1 & 0,143 \\
Gantungan Kunci & 0,007 & 0,007 \\
\hline Sumber : Data primer yang telah diolah 2018
\end{tabular}

Sumber : Data primer yang telah diolah 2018

\section{Biaya Tenaga Kerja}

Tenaga kerja yang dimiliki UD Betris berjumlah 3 orang sudah termasuk pemilik usaha. Upah tenaga kerja sehari adalah sebesar $\mathrm{Rp}$ 150.000 dengan jam kerja 8 jam. Jadi untuk 1 jam kerja upah yang dibayarkan adalah sebesar Rp 18.750. Waktu dan jam kerja yang dicurahkan dalam memproduksi 4 jenis kerajinan berbeda-beda. Waktu kerja yang dicurahkan untuk miniature rumah adat besar yaitu 4 hari, untuk miniature rumah adat kecil 5 hari, miniature bunga 1 hari, dan souvenir gantungan kunci hanya 30 menit dalam sehari. Upah tenaga kerja yang dibayarkan dihitung berdasarkan jam kerja yang dicurahkan dalam memproduksi masing-masing dari 4 jenis kerajinan tersebut.

3. Biaya listrik

Selama proses produksi kerajinan bambu tutul juga menggunakan listrik sehingga biaya yang dikeluarkan dalam proses ini wajib dihitung dan dimasukkan dalam biaya. biaya listrik keseluruhan dalam 1 bulan dari UD Betris adalah sebesar Rp 150.000. Dan yang digunakan dalam usaha hanya $5 \%$ yaitu sebesar Rp 7.500.

Tabel 5 menunjukkan bahwa biaya yang tertinggi ada pada produksi rumah adat kecil sebesar Rp 771.095 dikarenakan jangka waktu untuk pembuatan rumah kecil lebih lama dibanding jenis kerajinan yang lain.

Tabel 5. Biaya Variabel Rumah Adat Minahasa Besar (RAB), Rumah Adat Minahasa Kecil (RAK), Bunga, Gantungan Kunci UD Betris

\begin{tabular}{lrrrr}
\hline Komponen Biaya & RAB (Rp) & RAK (Rp) & Bunga (Rp) & $\begin{array}{r}\text { Gantungan } \\
\text { Kunci (Rp) }\end{array}$ \\
\hline Bambu & & & & 175 \\
Lem & 10.725 & 7.150 & 3.575 & 240 \\
Cat politer & 6.000 & 6.000 & 6.000 & 432 \\
Amplas & 5.400 & 4.320 & 2.160 & 200 \\
Gantungan kunci & 1.250 & 1.000 & 500 & 280 \\
Upah & 0 & 0 & 0 & 5.625 \\
Listrik & 600.000 & 750.000 & 150.000 & 375 \\
\hline Total Biaya Variabel & 626.000 & 2.625 & 1.500 & 7.327 \\
\hline Sumber : Data primer & 771.095 & 163.735 &
\end{tabular}

Sumber : Data primer yang telah diolah 2018

\section{Biaya}

Biaya total (total cost) adalah jumlah dari biaya tetap dan biaya variabel. Biaya total yang digunakan UD Betris untuk setiap jenis produk dapat dilihat pada Tabel 6 .

Tabel 6 menunjukkan total biaya tertinggi adalah jenis produk rumah adat kecil sebesar Rp 783.520 dikarenakan waktu yang dibutuhkan untuk membuat rumah adat kecil lebih lama dibandingkan dengan jenis produk yang lain. Dalam perhitungan ini semakin lama waktu yang digunakan semakin tinggi pula upah yang harus dibayarkan kepada tenaga kerja. Total biaya terendah adalah jenis produk gantungan kunci sebesar Rp 9.102. Tinggi rendahnya biaya variabel mempengaruhi total biaya. 
Tabel 6. Total Biaya Rumah Adat Minahasa Besar (RAB) Rumah Adat Minahasa Kecil (RAK), Bunga, Gantungan Kunci UD Betris

\begin{tabular}{lrrrr}
\hline Biaya & RAB (Rp) & RAK (Rp) & Bunga (Rp) & $\begin{array}{c}\text { Gantungan } \\
\text { Kunci (Rp) }\end{array}$ \\
\hline Biaya Tetap & 14.200 & 12.425 & 7.100 & 1.775 \\
Biaya Variabel & 626.375 & 771.095 & 163.735 & 7.327 \\
\hline Cat politer & 640.575 & 783.520 & 170.835 & 9.102 \\
\hline Sur
\end{tabular}

Sumber : Data primer yang telah diolah 2018

\section{Total Penerimaan}

Penerimaan adalah perkalian antara jumlah produksi dengan harga jual yang telah disepakati bersama antara penjual dan pembeli. Dalam kegiatan usaha, perusahaan selalu meningkatkan produksi dengan harapan bahwa pendapatan yang diterima akan naik sejalan dengan bertambahnya produksi yang dihasilkan.

Tabel 7. Penerimaan RAB, RAK, Bunga, Gantungan Kunci UD Betris

\begin{tabular}{lr}
\hline \multicolumn{1}{c}{ Jenis Kerajinan } & Pemerimaan \\
Miniature/Souvenir & per unit (Rp) \\
\hline Rumah Adat Besar (RAB) & 2.250 .000 \\
Rumah Adat Kecil (RAK) & 1.500 .000 \\
Bunga & 350.000 \\
Gantungan Kunci & 15.000 \\
\hline Sumber : Data primer yang telah diolah 2018
\end{tabular}

\section{Keuntungan}

Keuntungan merupakan selisih antara penerimaan dan semua biaya total produksi yang dikeluarkan UD Betris. Keuntungan yang diperoleh sangat tergantung dari jumlah penerimaan yang diterima dikurangi dengan biaya yang dikeluarkan, besarnya penerimaan yang didapat merupakan hasil perkalian antara harga jual produk dengan jumlah produksi yang dihasilkan sehingga semakin tinggi produksi dengan biaya semakin kecil dan harga akan mempengaruhi keuntungan.

Tabel 8 menunjukkan rumah adat besar memperoleh keuntungan yang paling tinggi sebesar $\mathrm{Rp}$ 1.609.425 dibandingkan dengan jenis produk yang lain. Rumah adat besar memperoleh keuntungan yang besar dikarenakan harga jualnya yang tinggi. Gantungan Kunci memperoleh nilai lebih kecil dari jenis produk kerajinan yang lain sebesar $\mathrm{Rp}$ 5.898. Gantungan kunci merupakan yang paling banyak diproduksi walaupun keuntungan yang diberikan dari satu unit gantungan kunci lebih kecil dari jenis kerajinan yang lain. Hal ini dikarenakan waktu pengerjaan atau proses produksi gantungan kunci lebih cepat dibanding jenis kerajinan lain.
Tabel 8. Keuntungan RAB, RAK, Bunga, Gantungan Kunci UD Betris

\begin{tabular}{lrrr}
\hline \multicolumn{1}{c}{ Jenis Kerajinan } & Penerimaan & Biaya & Keuntungan \\
Miniature/Souvenir & & & \\
\hline Rumah Adat Besar (RAB) & 2.250 .000 & 640.575 & 1.609 .425 \\
Rumah Adat Kecil (RAK) & 1.500 .000 & 783.520 & 716.480 \\
Bunga & 350.000 & 170.835 & 179.165 \\
Gantungan Kunci & 15.000 & 9.102 & 5.898 \\
\hline Sumber : Data primer yang telah diolah 2018 & &
\end{tabular}

\section{Analisis Revenue Cost Ratio}

Tingkat keuntungan ekonomi dapat diketahui dengan menggunakan Analisis Revenue Cost Ratio (R/C ratio) adalah perbandingan antara penerimaan dan biaya, ratio yang menjadi parameternya adalah nilai $\mathrm{R} / \mathrm{C}=1$ berarti usaha tidak untung atau tidak rugi, nilai $\mathrm{R} / \mathrm{C}<1$ berarti usaha rugi, nilai $\mathrm{R} / \mathrm{C}$ $>1$ berarti usaha untung. Nilai R/C untuk tiap jenis produk kerajinan UD Betris dapat dilihat pada Tabel 9.

Tabel 9 menunjukkan rumah adat besar memperoleh nilai $\mathrm{R} / \mathrm{C}$ tertinggi yaitu sebesar 3,513 yang artinya setiap 1,00 biaya yang dikeluarkan akan memberikan keuntungan sebesar 2,513. Sama halnya dengan rumah adat kecil 1,914, Bunga 2,049, Gantungan Kunci 1,648 maka dapat dinilai berdasarkan kriteria diatas Rumah Adat Besar, Rumah Adat Kecil, Bunga, Gantungan Kunci memberikan keuntungan.

Tabel 9. Revenue Cost RAB, RAK, Bunga, Gantungan Kunci UD Betris

\begin{tabular}{lr}
\multicolumn{1}{c}{ Jenis Kerajinan } & \multicolumn{1}{c}{ Pemerimaan } \\
Miniature/Souvenir & per unit (Rp) \\
\hline Rumah Adat Besar (RAB) & 2.250 .000 \\
Rumah Adat Kecil (RAK) & 1.500 .000 \\
Bunga & 350.000 \\
Gantungan Kunci & 15.000 \\
\hline Sumber : Data primer yang telah diolah 2018
\end{tabular}

\section{KESIMPULAN DAN SARAN}

\section{Kesimpulan}

Keuntungan Usaha Kerajinan Bambu Tutul UD Betris Di Kelurahan Meras Kecamatan Bunaken Kota Manado dari jenis produk kerajinan miniature rumah adat besar, miniature rumah adat kecil, miniature bunga, dan souvenir gantungan kunci berbeda-beda. Keuntungan yang diperoleh dari Rumah Adat Besar sebesar Rp 1.609.425, Rumah Adat Kecil sebesar Rp 716.480, Bunga sebesar Rp 179.165, dan Gantungan Kunci sebesar Rp 5.898. R/C rasio 
untuk setiap jenis produk juga berbeda-beda. Rumah Adat Besar memperoleh nilai R/C 3,513, Rumah Adat Kecil memperoleh nilai R/C 1,914, Bunga memperoleh nilai R/C 2,049, dan gantungan kunci memperoleh nilai R/C 1,648 yang berarti menguntungkan.

\section{Saran}

Berkaitan dengan hasil penelitian ini, maka usaha ini perlu adanya pencatatan atau pembukuan yang tertulis agar dapat diketahui berapa total biaya yang dikeluarkan dan berapa jumlah penerimaan yang diterima sehingga dapat diketahui dengan pasti keuntungan atau kerugian yang didapat. Usaha kerajinan bambu tutul UD Betris merupakan satu-satunya industri rumah tangga yang mengolah bambu tutul menjadi bentuk kerajinan yang unik dan beragam oleh sebab itu usaha ini harus terus dikembangkan degan memperhatikan komponen-komponen biaya yang dikeluarkan.

\section{DAFTAR PUSTAKA}

Arief, A. 2001. Hutan dan Kehutanan. Kanisius. Scholar google.co.id.

Dewi, M. T. 2018. Analisis Keuntungan Usaha CV Indospice Di Tuminting Kota Manado. Skripsi Fakultas Pertanian Unsrat.

Nurfatriani, F. 2006. Konsep Nilai Ekonomi Total Dan Metode Penilaian Sumberdaya Hutan. Jurnal Penelitian Sosial Dan Ekonomi Kehutanan. Ejournal Fordamof.Org.

Setiawan, B. 2017. Strategi Pengembangan Kerajinan Bambu Di Wilayah Kampung Pajeleran Sukahati Kecamatan Cibinong Kabupaten Bogor. Scholar google.co.id. 